\title{
Extracellular heat shock protein $90 a$ mediates HDM-induced bronchial epithelial barrier dysfunction by activating RhoA/MLC signaling
}

Hang-ming Dong ${ }^{1+}$, Yan-qing Le ${ }^{1 \dagger}$, Yan-hong Wang ${ }^{1 \dagger}$, Hai-jin Zhao ${ }^{1}$, Chao-wen Huang ${ }^{1}$, Ya-hui Hu', Li-shan Luo ${ }^{1}$, Xuan Wan ${ }^{1}$, Yi-lan Wei ${ }^{1}$, Zi-qiang Chu', Wei Li ${ }^{2}$ and Shao-xi Cai ${ }^{*}$

\begin{abstract}
Background: The disruption and hyperpermeability of bronchial epithelial barrier are closely related to the pathogenesis of asthma. House dust mite (HDM), one of the most important allergens, could increase the airway epithelial permeability. Heat shock protein (Hsp) 90a is also implicated in the lung endothelial barrier dysfunction by disrupting RhoA signaling. However, the effect of extracellular Hsp90a (eHsp90a) on the bronchial epithelial barrier disruption induced by HDM has never been reported.
\end{abstract}

Methods: To investigate the involvement of eHsp90a in the bronchial epithelial barrier disruption induced by HDM, normal human bronchial epithelial cell line 16HBE140- (16HBE) cells were treated by HDM, human recombinant (hr) Hsp90a and hrHsp90ß respectively and pretreated by 1 G6-D7, a specific anti-secreted Hsp90a monoclonal antibody (mAb). Hsp90a-silencing cells were also constructed. To further evaluate the role of RhoA signaling in this process, cells were pretreated by inhibitors of Rho kinase, GSK429286A and Y27632 2HCl. Transepithelial electrical resistance (TEER) and FITC-dextran flux (FITC-DX) were examined as the epithelial barrier function. Expression and localization of adherens junctional proteins E-cadherin and $\beta$-catenin were evaluated by western blotting and immunofluorescence respectively. The level of eHsp90a was investigated by concentration and purification of condition media. RhoA activity was determined by using a Rho G-LISA ${ }^{\oplus}$ RhoA activation assay kit ${ }^{\mathrm{TM}}$ biochem kit, and the phosphorylation of myosin light chain (MLC), the downstream signal molecule of RhoA, was assessed by western blotting.

Results: The epithelial barrier disruption and the loss of adherens junctional proteins E-cadherin and $\beta$-catenin in cytomembrane were observed in HDM-treated 16HBE cells, paralleled with the increase of eHsp90a secretion. All of which were rescued in Hsp90a-silencing cells or by pretreating 16HBE cells with 1G6-D7. Also, 1G6-D7 suppressed RhoA activity and MLC phosphorylation induced by HDM. Furthermore, inhibitors of Rho kinase prevented and restored the airway barrier disruption. Consistently, it was hrHsp90a instead of hrHsp90ß that promoted barrier dysfunction and activated RhoA/MLC signaling in 16HBE cells.

Conclusions: The eHsp90a mediates HDM-induced human bronchial epithelial barrier dysfunction by activating RhoA/MLC signaling, suggesting that eHsp90a is a potential therapeutic target for treatment of asthma.

Keywords: Bronchial epithelial, Barrier dysfunction, Extracellular heat shock protein90a, RhoA/MLC signaling, House dust mite

\footnotetext{
* Correspondence: caishaox@fimmu.com

${ }^{\dagger}$ Equal contributors

${ }^{1}$ Chronic Airways Diseases Laboratory, Department of Respiratory and Critical

Care Medicine, NanFang Hospital, Southern Medical University, Guangzhou

510515, China

Full list of author information is available at the end of the article
} 


\section{Background}

The airway epithelium forms a continuous, highly regulated physical barrier lining of the airway lumen, prevents invasion of inhaled environmental agents such as aeroallergens, pollutants and pathogens [1]. Intercellular junctions are comprised of tight junctions (TJs), adherens junctions (AJs) and desmosomes [1]. Presence of dysfunctional epithelial barrier in the asthmatic airway included hyperpermeability to allergens and disrupted expression of the junction molecule E-cadherin at sites of epithelial detachment [2,3]. The decrease of epithelial E-cadherin protein expression in patients with atopic asthma contributed to defective airway epithelial barrier $[4,5]$. E-cadherin/ $\beta$-catenin complex, the AJs complex (AJC), plays an important role in maintaining epithelial integrity and disrupting this complex affect not only the adhesive repertoire of a cell, but also the Wnt-signaling pathway [6], leading to the initiation and chronicity of asthma. Furthermore, dysregulation of epithelial repair in asthmatic airways, including epithelial-mesenchymal transition, contributed to asthmatic airway remodeling [7].

Heat shock protein (Hsp) 90 is an essential molecular chaperone in eukaryotic cells with an important role in activation and maintenance of numerous regulatory and signaling proteins [8]. Since many of Hsp90 clients are oncogenic proteins, Hsp90 has become a therapeutic target for treatment of cancer. However, tumor cells have managed to constitutively secrete $\mathrm{Hsp} 90$ for tissue invasion, whereas normal cells also secrete Hsp90 in response to tissue injury [9]. Abundant evidences also showed that Hsp90 inhibitors protected and restored pulmonary endothelial barrier dysfunction [10-12]. Furthermore, Tong W, et al. reported that higher expression of Hsp90 mRNA and protein were detected in asthmatic patients than healthy controls [13, 14]. Hsp90 contributed to deterioration of airway inflammation in an ovalbumininduced murine asthma model [15]. Also, inhibition of Hsp90 decreased the relaxation of tracheal ring in asthmatic mice [16]. Fundamental distinctions between intracellular and extracellular Hsp90 are clear. Both Hsp90 $\alpha$ isoform and $\mathrm{Hsp} 90 \beta$ isoform can be secreted to extracellular space. Hsp90 $\beta$ mainly acts as a molecular chaperone protein that maintains the intracellular signaling networks essential for life [17]. Mice lacking Hsp90 $\beta$ failed to develop a placental labyrinth [18]. However, Hsp90 $\alpha$ exerts pro-mobility signal after being secreted to extracellular environment by cells stimulated with heat [19], hypoxia $[20,21]$, gamma-irradiation [21] or tissue injury-released cytokines, such as TGF- $\alpha$ [22]. Extracellular Hsp90 participated in TGF- $\beta$-mediated collagen production in myocardial fibroblasts [23], wound healing in keratinocytes $[9,24]$ and contributed to tumor growth, invasion, and inflammatory storm [9, 25-29]. These findings prompted us to investigate the role of extracellular Hsp90 $\alpha$ (eHsp90 $\alpha)$ in HDM-induced airway barrier dysfunction. A newly generated mAb, 1G6-D7, which selectively targets the dual lysine region in secreted Hsp90 $\alpha$, represents a viable anticancer agent $[30,31]$. Therefore, we also used 1G6-D7 in this study to evaluate the role of eHsp90 $\alpha$ in airway barrier disruption.

The Rho family of small GTPases plays an important role in a variety of cellular responses, including contraction, motility and proliferation and barrier dysfunction [32-34]. Rho kinase (ROCK) is activated by RhoA-GTP, and induces phosphorylation of myosin light chain (MLC), the downstream molecule of Rho. Then phosphorylated MLC regulates cellular contraction and promotes cytoskeletal reorganization [11, 35, 36]. Studies revealed that RhoA signaling was involved in intestinal and prostate epithelial barrier hyperpermeability [37, 38]. Hyaluronan and layilin mediated loss of airway epithelial barrier function induced by cigarette smoke by Rho/ROCK signaling to decrease E-cadherin, leading to a loss of epithelial cell-cell contact [39]. Moreover, inhibition of Hsp90 prevented LPS-induced lung endothelial barrier dysfunction by disrupting RhoA signaling [11], suggesting a role for Hsp90 in regulating RhoA signaling. These indicated that activated RhoA signaling resulted in increased epithelial and endothelial permeability. Thus, we hypothesized that eHsp $90 \alpha$ mediated HDM-induced bronchial epithelial barrier dysfunction via activating RhoA/MLC signaling.

\section{Methods}

\section{Antibodies and reagents}

HDM, 100000 SQ-U (U)/ml in Alutard, was purchased from ALK-Abello A/S (Guangzhou, China). 1G6-D7 (noncommercial antibody), the anti-secreted Hsp90 $\alpha$ $\mathrm{mAb}$, was kindly granted by the University of Southern California Keck School of Medicine in USA. The Rho kinase inhibitors, Y-27632 2HCl (S1049) and GSK429286A (S1474), were obtained from Selleck Chemicals (Shanghai, China). Human recombinant (hr) Hsp90 $\alpha$ (SPR-101C) and hrHsp90 $\beta$ (SPR-102C) were purchased from Stressmarq Bioscience (Victori, Canada). Anti- $\beta$-actin(8457), anti-MLC(3672), anti-phospho(p)-MLC(3674) antibodies and horseradish peroxidase (HRP)-conjugated donkey antirabbit or anti-mouse IgG antibodies were purchased from Cell Signaling Technology (Beverly, USA). AntiHsp90 antibody (CA1023) was obtained from Calbiochem (Billerica, USA) and anti-Hsp90 $\beta$ antibody (SMC 107) was from Stressmarq Biosciences (Victoria, Canada). Anti-Ecadherin (sc-7870) and anti- $\beta$-catenin (sc-7199) antibodies were purchased from Santa Cruz Biotechnologies (Santa Cruz, USA). Alexa 488-labeled goat anti-rabbit secondary antibody was from Life Technologies (Grand Island, USA). 


\section{Cell culture and treatment}

Human bronchial epithelial cell line 16HBE14o- (16HBE) cells were purchased from Bio-Rad Biological Technology Co. Ltd (Shanghai, China), which was the agent of ATCC. Cells were cultured in RPMI-1640 medium containing $10 \%$ fetal calf serum at $37{ }^{\circ} \mathrm{C}$ and $5 \% \mathrm{CO}_{2}$ incubator. When reaching 90\% confluence, the cells were seeded to proper culture plates at a density of $10^{4}-10^{5}$ cells/ $\mathrm{cm}^{2}$. After $24 \mathrm{~h}$ incubation, the culture medium was changed into serum free RPMI-1640. Different concentrations of HDM, hrHsp90 $\alpha$ or hrHsp90 $\beta$ were added to the culture medium for indicated times partly based on previous studies $[17,40,41]$.

\section{Measurement of transepithelial electrical resistance (TEER) and FITC-dextran flux (FITC-DX)}

Confluent monolayers of $16 \mathrm{HBE}$ cells were cultured in 12-well Transwell inserts, purchased from Corning Company. Based on previous studies [42, 43], cells were seeded into 12-well transwell inserts duplicates (density of $2 * 10^{5} /$ well) and complete confluence was reached almost for 3 additional days. TEER was measured by using a Millicell ERS-2 Epithelial Volt-Ohm meter with an STX01 electrode (MA, USA), and the levels were normalized to medium only (con) group.

Confluent monolayers of $16 \mathrm{HBE}$ cells were cultured in 24-well Transwell inserts. Cells were seeded into 24-well transwell inserts duplicates (density of $1 * 10^{5} /$ well) and complete confluence was reached almost for 3 additional days. FITC-DX, purchased from Sigma Company, was added to the upper chamber followed by incubation for $1 \mathrm{~h}$ at $37^{\circ} \mathrm{C}$ before the $100 \mu \mathrm{l}$ liquid from both chambers was removed. Fluorescence values were measured by using a fluorescent plate reader (Männedorf, Switzerland). The values of FITC-DX permeability were normalized to the con group, which was denoted by $\mathrm{Pa} / \mathrm{Pc} \%$.

\section{Immunofluorescence staining}

The cell monolayers were grown on glass bottom cell culture dishes (Guangzhou, China) and were fixed in $4 \%$ paraformaldehyde at room temperature for $30 \mathrm{~min}$ before washing with PBS (5 $\mathrm{min} \times 3$ times), then incubated with $0.2 \%$ Triton $\mathrm{X}-100$ in PBS for $10 \mathrm{~min}$, and washed again with PBS. The cells were blocked with 5\% skim milk in PBS for $3 \mathrm{~h}$ and then incubated overnight with a primary antibody (E-cadherin or $\beta$-catenin) at $4{ }^{\circ} \mathrm{C}$. Then cell monolayers were incubated with alexa 488 -labeled goat anti-rabbit secondary antibody for $1 \mathrm{~h}$ at $37{ }^{\circ} \mathrm{C}$ in the dark and washed again with PBS. 4', 6-diamidino-2phenylindole dihydrochloride (DAPI) (Shanghai, China) was added to stain the cell nucleus for $10 \mathrm{~min}$. A laser scanning confocal microscope (Tokyo, Japan) was used to examine the location of E-cadherin and $\beta$-catenin in the $16 \mathrm{HBE}$ cells.

\section{RhoA activity assay}

RhoA activity was determined by using a Rho G-LISA ${ }^{\odot}$ RhoA activation assay $\mathrm{kit}^{\mathrm{TM}}$ biochem kit according to the manufacturer's instructions (Denver, USA). Results were normalized to protein levels measured by the Precision Red protein assay reagent.

\section{Concentration and purification of condition media}

The condition media of $16 \mathrm{HBE}$ cells treated by HDM was collected for centrifugation at $1500 \mathrm{~g}$ for $5 \mathrm{~min}$. Then the supernatants were added to centrifugal filter units from Millipore Company (Bedford, MA) for concentration and purification following the manufacturer's instructions. Finally the concentrated and purified supernatants were prepared for detecting the level of eHsp90 $\alpha$ protein by Western blotting analysis.

\section{Lentiviral systems for silencing of Hsp90a protein}

Lentiviral systems for knocking down the Hsp90 $\alpha$ gene were completed by Hanbio Biotechnology Co. Ltd (Shanghai, China). The cDNAs sequence for human Hsp90 $\alpha$ was 5'-GGAAAGAGCTGCATATTAA-3'. Wildtype or mutant Hsp90 $\alpha$ cDNAs was inserted into the lentivirus-derived vector. These constructs were used to transfect $16 \mathrm{HBE}$ cells. The transfect $16 \mathrm{HBE}$ cells were respectively named Sh-Hsp90 $\alpha$ and Sh-LacZ cells. Silencing of the endogenous Hsp90 $\alpha$ protein product was identified by western blotting analysis.

\section{Western blotting analysis}

To evaluate the protein expression of Hsp90 $\alpha$, Hsp90 $\beta$, E-cadherin, $\beta$-catenin, MLC, and p-MLC, Total cell lysates were subjected to $10 \%$ or $12 \%$ SDS-PAGE, transferred to PVDF membrane (Bedford, MA), and then probed with the following antibodies: Hsp90 $\alpha$, Hsp90 $\beta$, MLC, p-MLC, E-cadherin and $\beta$-catenin. After incubation with an IRDye ${ }^{\circledast} 680 \mathrm{WC}$-conjugated secondary antibody (LI-COR Biosciences), immunoreactive bands were exposed to Odyssey ${ }^{\circ}$ CLx Imager for image capture. Or after incubation with horseradish peroxidase (HRP)-conjugated donkey anti-rabbit or anti-mouse IgG antibody, the immunoreactive bands were detected using the enhanced chemiluminescence from Millipore Company (Bedford, MA). Quantitative image analysis was performed with Image J software.

\section{Statistical analysis}

SPSS 20.0 software was used for the statistical analyses. Statistical analysis was performed by one-way analysis of variance (ANOVA) and post hoc tests were analyzed by Bonferonni (equal variances assumed) or Dunnett's T3 (equal variances not assumed) post hoc tests for multiple comparisons. Results were presented as mean \pm standard deviations (SD). $P<0.05$ was 
considered to be statistically significant. At least three independent experiments were repeated.

\section{Results}

HDM induced bronchial epithelial hyperpermeability

To clarify the effect of HDM on loss of bronchial epithelial barrier integrity, 16HBE cells were stimulated with different concentrations of HDM $(200,400,800 \mathrm{U} / \mathrm{ml})$ for $24 \mathrm{~h}$, which were used for measurement of TEER and FITC-DX. Results indicated that HDM $(400 \mathrm{U} / \mathrm{ml}$ or $800 \mathrm{U} / \mathrm{ml})$ induced the fall of TEER values (Fig. 1a, $P<0.05$ ) and the raise of FITC-DX (Fig. 1b, $P<0.05$ ) compared to con group, suggesting that HDM induced bronchial epithelial hyperpermeability.

\section{HDM induced delocalization of E-cadherin and $\beta$-catenin}

E-cadherin/ $\beta$-catenin complex plays an important role in maintaining epithelial integrity [6]. Here we further detected the effect of HDM on E-cadherin/ $\beta$-catenin complex in $16 \mathrm{HBE}$ cells. Cells were exposed to different concentrations of $\mathrm{HDM}(200,400,800 \mathrm{U} / \mathrm{ml})$ for $24 \mathrm{~h}$. Western blotting analysis revealed that HDM treatment did not affect the expression of E-cadherin or $\beta$-catenin in $16 \mathrm{HBE}$ cells (Fig. 1c-d, $P>0.05$ ). However, the immunofluorescence showed that HDM promoted delocalization
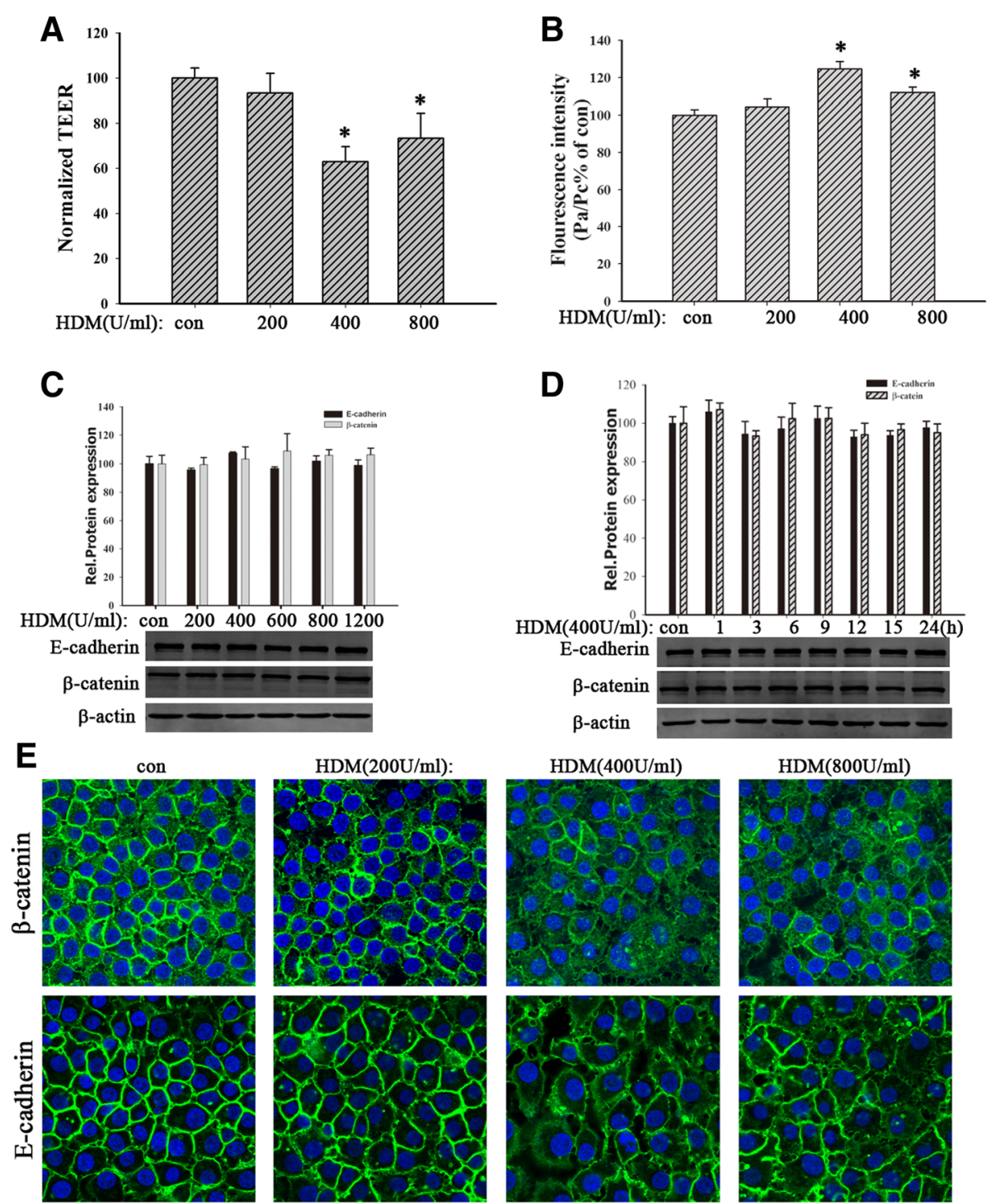

Fig. $1 \mathrm{HDM}$ induced bronchial epithelial hyperpermeability and E-cadherin and $\beta$-catenin delocalization. $\mathbf{a}$ and $\mathbf{b}) 16 \mathrm{HBE}$ cells were exposed to $\operatorname{HDM}(200,400$, or $800 \mathrm{U} / \mathrm{ml})$ for $24 \mathrm{~h}$. TEER values and FITC-DX were measured immediately. $\mathbf{c}$ and $\mathbf{d}) 16 \mathrm{HBE}$ cells were treated with HDM (200, $400,600,800$ or $1200 \mathrm{U} / \mathrm{ml}$ ) for $24 \mathrm{~h}$ or stimulated with HDM (400 U/ml) for 1, 3, 6, 9, 12, 15 or $24 \mathrm{~h}$. The expression of E-cadherin and $\beta$-catenin proteins was detected by Western blotting analysis in total lysates. $\mathbf{e}$ The location of E-cadherin and $\beta$-catenin was detected by immunofluorescence staining. Data are mean \pm SD of four independent experiments. ${ }^{*} P<0.05$ versus con group 
of E-cadherin and $\beta$-catenin, exhibiting discontinuous and diffusing from the adjacent cell borders to cytoplasm (Fig. 1e). These results indicated that HDM induced the abnormal distribution of E-cadherin and $\beta$-catenin in $16 \mathrm{HBE}$ cells. It suggested that HDM could induce bronchial epithelial barrier dysfunction by disrupting the localization of $E$-cadherin $/ \beta$-catenin complex in cell-cell contact.

\section{HDM promoted the expression and secretion of Hsp90a in $16 \mathrm{HBE}$ cells}

Normal cells could secrete Hsp90 $\alpha$ in response to injury stimulations [9]. Thus, we investigated whether HDM induced secretion of $\mathrm{Hsp} 90 \alpha$ in $16 \mathrm{HBE}$ cells. Cells were stimulated by different concentrations of HDM (200, $400,800 \mathrm{U} / \mathrm{ml})$ for $24 \mathrm{~h}$ or by HDM $(400 \mathrm{U} / \mathrm{ml})$ for indicated time $(1,3,6,12,24$ or $48 \mathrm{~h})$. Then the supernatants were collected for concentration and purification to detect eHsp90 $\alpha$. Western blotting analysis revealed that HDM induced a significant increase of Hsp90 $\alpha$ at $400 \mathrm{U} / \mathrm{ml}$ (Fig. 2a). The eHsp90 $\alpha$ protein was detected from $12 \mathrm{~h}$ and accumulated in a time-dependent manner (Fig. 2b). It suggested that HDM promoted the secretion of Hsp90a. Besides, we extracted the total cell lysates to detect the level of intracellular Hsp90 $\alpha$. Results showed the intracellular Hsp90 $\alpha$ also was increased in HDMexposed cells (Fig. 2c-d, $P<0.05$ ). Therefore, these data indicated that HDM increased both intracellular and extracellular Hsp90 $\alpha$ protein expression in 16HBE cells.

HrHsp90a induced bronchial epithelial hyperpermeability To identify whether Hsp90 $\alpha$ contributed to HDMinduced airway epithelial barrier disruption, cells were treated by hrHsp90 $\alpha(10,40 \mu \mathrm{g} / \mathrm{ml})$ or hrHsp90 $\beta(10$, $40 \mu \mathrm{g} / \mathrm{ml}$ ) for $24 \mathrm{~h}$. Results indicated that it was hrHsp90 $\alpha$ instead of hrHsp90 $\beta$ that induced the fall of

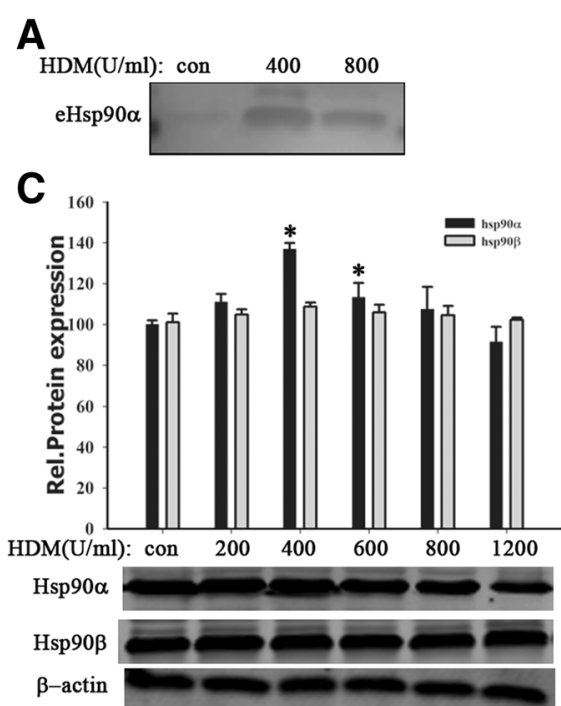

E

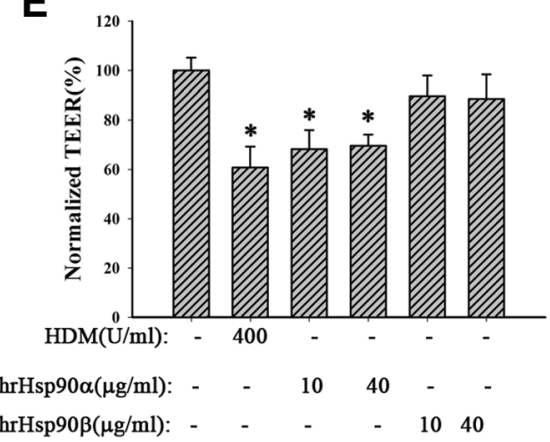

B
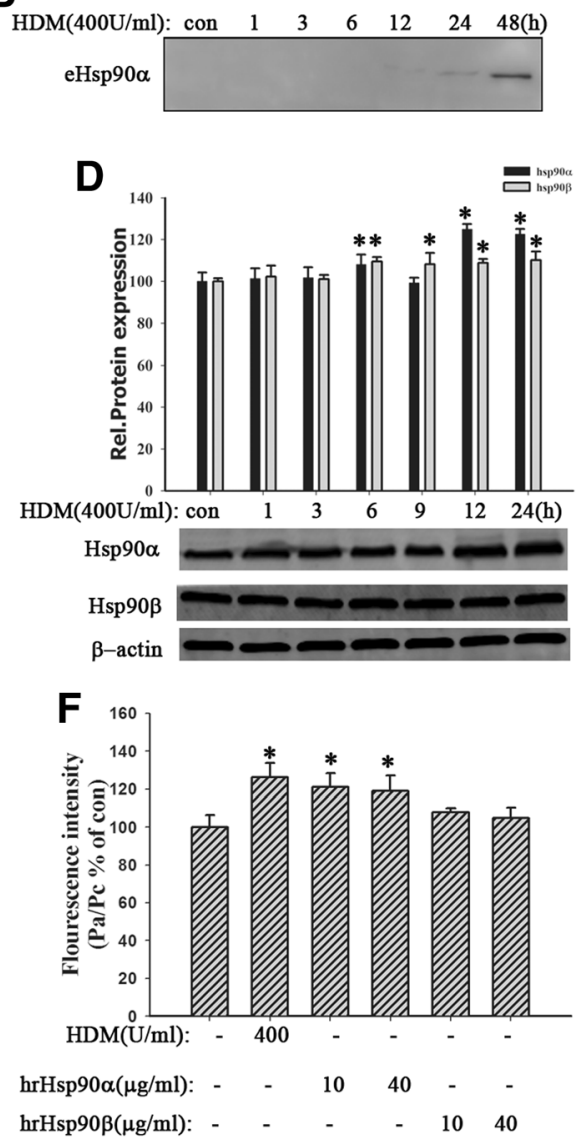

Fig. 2 HDM promoted the expression and secretion of Hsp90a and hrHsp90a induced bronchial epithelial hyperpermeability. a and b 16HBE cells were exposed to HDM (400 or $800 \mathrm{U} / \mathrm{ml}$ ) for $24 \mathrm{~h}$ or stimulated with HDM (400 U/ml) for 1, 3, 6, 12, 24, or 48 h. The supernatants were collected for detecting eHsp90a by western blotting analysis. c and d 16HBE cells were treated with HDM (200, 400, 600, 800, or 1200 U/ml) for $24 \mathrm{~h}$ or stimulated with $\mathrm{HDM}(400 \mathrm{U} / \mathrm{ml})$ for 1, 3, 6, 9, 12, or $24 \mathrm{~h}$. The expression of Hsp90a and Hsp90 3 was detected by western blotting analysis. e and $\mathbf{f}$ Cells were exposed to HDM (400 U/ml), hrHsp90a (10, $40 \mu \mathrm{g} / \mathrm{ml})$, or hrHsp90ß (10, $40 \mu \mathrm{g} / \mathrm{ml})$ for 24 h. TEER values and FITC-DX were measured. Data are mean \pm SD of three independent experiments. ${ }^{*} P<0.05$ versus con group 
TEER values (Fig. $2 \mathrm{e}, P<0.05)$ and the raise of FITC-DX (Fig. 2f, $P<0.05$ ), suggesting hrHsp90 $\alpha$ induced bronchial epithelial hyperpermeability. Collectively, these data indicated that Hsp90a probably played a critical role in HDM-induced bronchial epithelial barrier dysfunction.

\section{Hsp90a-silencing alleviated HDM-induced barrier dysfunction}

Other studies showed that Hsp90 inhibitors protected and restored the loss of microvascular endothelial and intestinal epithelial barrier integrity [10, 44]. Our data above also demonstrated that $\mathrm{Hsp} 90 \alpha$ played a key role in HDM-induced barrier dysfunction. To further evaluate the role of Hsp90 $\alpha$ in HDM-induced barrier dysfunction, we successfully constructed lentivirus system for Hsp90 $\alpha$-silencing in $16 \mathrm{HBE}$ cells (Fig. 3a). The shHsp90 $\alpha$ cells were grown on transwell plates and then were exposed to HDM $(400 \mathrm{U} / \mathrm{ml})$ for $24 \mathrm{~h}$. Results showed that Hsp90 $\alpha$-silencing alleviated HDM-induced barrier dysfunction by improving TEER values and
FITC-DX (Fig. 3b-c, $P<0.05$ ). Collectively, these results demonstrated that Hsp90 $\alpha$ mediated HDM-induced bronchial epithelial barrier dysfunction.

\section{G6-D7restored HDM-induced bronchial epithelial barrier dysfunction}

1G6-D7, a newly generated mAb which selectively targets the dual lysine region in secreted $\mathrm{Hsp} 90 \alpha$, recognizes and neutralizes the eHsp90 $\alpha$ function [30, 31]. To identify that1G6-D7 inhibited HDM-induced airway epithelial barrier disruption via blocking eHsp90 $\alpha$ function, cells were pretreated with1G6-D7 $(30 \mu \mathrm{g} / \mathrm{ml})$ for $2 \mathrm{~h}$ and following stimulated by HDM $(400 \mathrm{U} / \mathrm{ml})$ for $24 \mathrm{~h}$. Results indicated that 1G6-D7 pretreatment exhibited a significant attenuation in the fall of TEER value (Fig. 3d, $P<0.05$ ) and the raise of FITC-DX (Fig. 3e, $P<0.05$ ), suggesting that eHsp90 $\alpha$ was involved in the HDM-induced epithelial hyperpermeability. Furthermore, the immunofluorescence also revealed that 1G6-D7 restored HDM-induced delocalization of E-

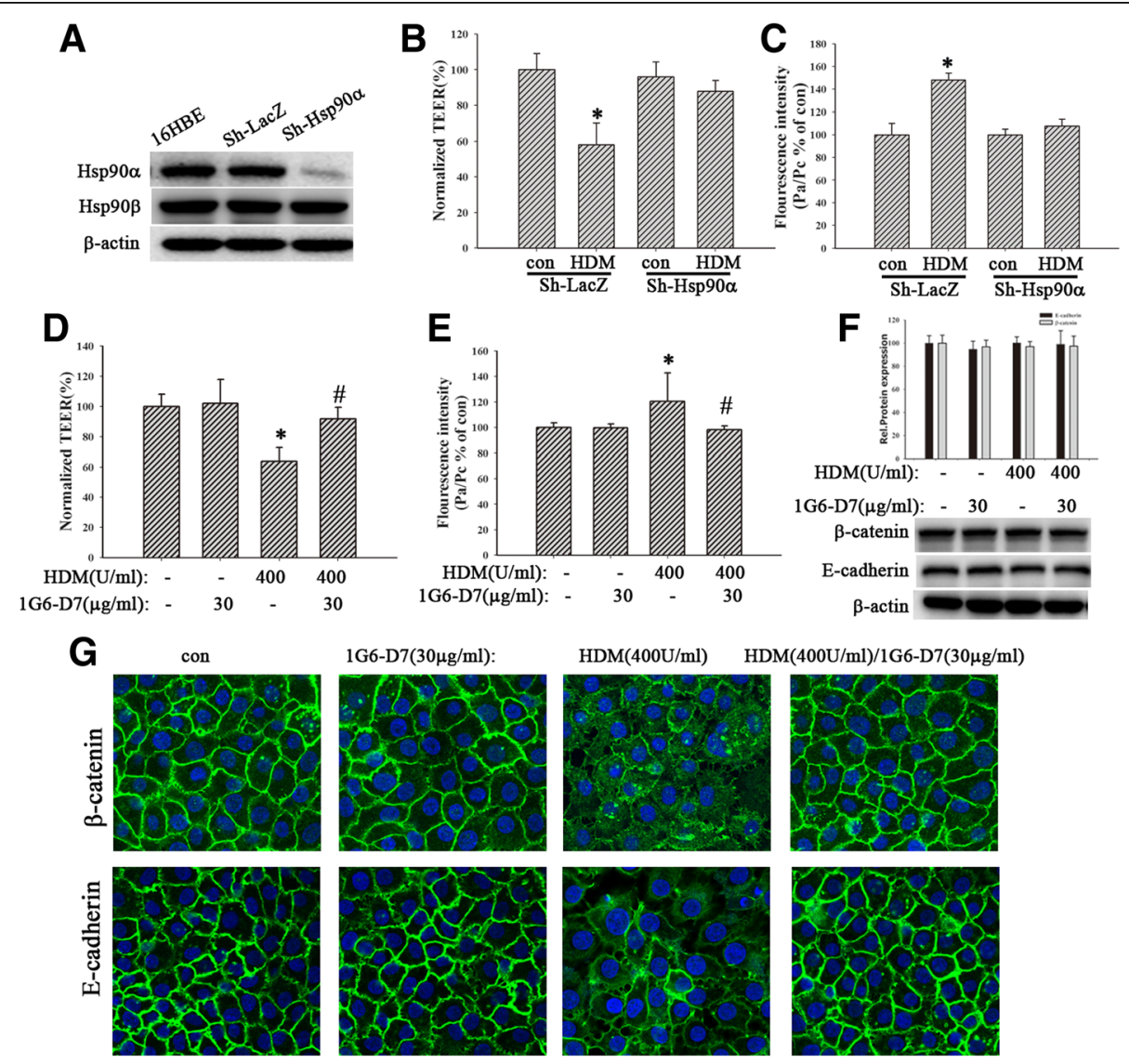

Fig. 3 Both silencing of Hsp90a and the eHsp90a mAb, 1G6-D7, restored HDM-induced epithelial barrier dysfunction. a The expression of Hsp90a in sh-Hsp90a group decreased remarkably. b and c Sh-Hsp90a cells were treated with HDM (400 U/ml) for $24 \mathrm{~h}$, then TEER values and FITC-DX were measured immediately. $\mathbf{d}$ and e Cells were pretreated with 1G6-D7 (30 $\mathrm{\mu g} / \mathrm{ml})$ for $2 \mathrm{~h}$ and then treated with HDM (400 U/ml) for $24 \mathrm{~h}$. TEER values and FITC-DX were measured. fThe expression of E-cadherin and $\beta$-catenin proteins was detected by western blotting analysis. $\mathbf{g}$ Immunofluorescence staining was used to show the localization of E-cadherin or $\beta$-catenin. Data are mean \pm SD of four independent experiments. ${ }^{*} P<0.05$ versus con group; ${ }^{\#} P<0.05$ versus HDM group 
cadherin and $\beta$-catenin (Fig. 3g), instead of affecting their expression (Fig. 3f, $P>0.05$ ).

\section{Inhibition of RhoA/MLC signaling alleviated bronchial epithelial barrier dysfunction}

RhoA and Rho kinase were involved in lysophosphatidic acid- and thrombin-induced endothelial barrier dysfunction [33, 34, 45]. Hsp90 inhibitors prevented LPSinduced endothelial barrier dysfunction by disrupting RhoA signaling [11]. Thus, we inferred that RhoA signaling might mediate the involvement of eHsp90 $\alpha$ in HDM-induced bronchial epithelial barrier dysfunction. Cells were pretreated by the Rho kinase inhibitors, Y$276322 \mathrm{HCl}(10,100 \mu \mathrm{M})$ and GSK429286A (10, $100 \mu \mathrm{M})$, for $6 \mathrm{~h}$ and then stimulated with HDM (400 $\mathrm{U} / \mathrm{ml}$ ) for $24 \mathrm{~h}$. Results showed that both inhibitors restored the fall of TEER and the raise of FITC-DX (Fig. 4a-b, $P<0.05)$. Besides, cells were pretreated with Y-27632 $2 \mathrm{HCl}(10 \mu \mathrm{M})$ or GSK429286A $(10 \mu \mathrm{M})$ for 2,4 or $6 \mathrm{~h}$ and then exposed to HDM $(400 \mathrm{U} / \mathrm{ml})$ for $24 \mathrm{~h}$. The immunofluorescence revealed that HDM induced the discontinuity and diffusing of E-cadherin and $\beta$ catenin, which were restored by Rho kinase inhibitors (Fig. 4e). The protein expression of E-cadherin and $\beta$ catenin had no statistical difference in both Rho kinase inhibitors groups (Fig. 4d, $P>0.05$ ). These data demonstrated RhoA/MLC signaling may mediate the involvement of eHsp90 $\alpha$ in HDM-induced bronchial epithelial barrier dysfunction.

\section{Both HDM and hrHsp90a induced RhoA activity and MLC phosphorylation}

To clarify the involvement of RhoA/MLC signaling in loss of bronchial epithelial barrier integrity, cells were exposed to different concentrations of HDM (200,400, $600,800$ or $1200 \mathrm{U} / \mathrm{ml})$ for $24 \mathrm{~h}$ or $\operatorname{HDM}(400 \mathrm{U} / \mathrm{ml})$ for indicated time $(3,6,12,24$ or $48 \mathrm{~h})$. Western blotting analysis indicated that HDM $(400 \mathrm{U} / \mathrm{ml})$ increased MLC phosphorylation beginning $6 \mathrm{~h}$ posttreatment, which remained elevated for many hours (Fig. 5a-b, $P<0.05$ ). Meanwhile, cells were pretreated by Y-27632 $2 \mathrm{HCl}$ $(10 \mu \mathrm{M})$ and GSK429286A $(10 \mu \mathrm{M})$ respectively for $6 \mathrm{~h}$ before treatment with HDM (400 U/ml) for $24 \mathrm{~h}$. Results showed that both inhibitors decreased the expression of p-MLC (Fig. 4c, $P<0.05$ ). Similarly, 16HBE cells exposed

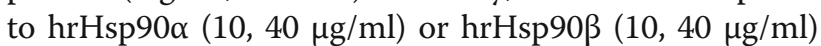
for $24 \mathrm{~h}$. The results revealed that hrHsp90 $\alpha$ instead of hrHsp90 $\beta$ induced MLC phosphorylation (Fig. 5c, $P<$ 0.05). Furthermore, we also found that HDM $(400 \mathrm{U} / \mathrm{ml})$ increased RhoA activity at $6 \mathrm{~h}$. Similarly, hrHsp90 $\alpha(10 \mu \mathrm{g} /$ $\mathrm{ml})$ instead of hrHsp90 $\beta(10 \mu \mathrm{g} / \mathrm{ml})$ also promoted the activation of RhoA signaling (Fig. $5 \mathrm{~d}-\mathrm{e}, P<0.05$ ). These data demonstrated that HDM and hrHsp90 $\alpha$ activated RhoA/
MLC signaling, contributing to bronchial epithelial barrier dysfunction.

\section{Inhibition of Hsp90a suppressed RhoA activity and MLC phosphorylation}

In order to further investigate the exact relationship between eHsp90 $\alpha$ and RhoA/MLC signaling, cells were pretreated by $1 \mathrm{G} 6-\mathrm{D} 7(30 \mu \mathrm{g} / \mathrm{ml})$ for $2 \mathrm{~h}$, then stimulated by $\operatorname{HDM}(400 \mathrm{U} / \mathrm{ml})$, hrHsp90 $\alpha(10 \mu \mathrm{g} / \mathrm{ml})$ or hrHsp90 $3(10 \mu \mathrm{g} / \mathrm{ml})$ for $24 \mathrm{~h}$. Results showed that 1G6D7 attenuated HDM-induced RhoA activity (Fig. 5e, $P<$ 0.05). Next we found that HDM induced robust MLC phosphorylation at $24 \mathrm{~h}$, while it was partly blocked by 1G6-D7 (30 $\mu \mathrm{g} / \mathrm{ml})$ (Fig. 6a, $P<0.05)$, suggesting that inhibition of eHsp90 $\alpha$ suppressed HDM-mediated MLC phosphorylation. Similarly, Hsp $90 \alpha$-silencing suppressed HDM-induced RhoA activity (Fig. 6c, $P>0.05$ ) and MLC phosphorylation (Fig. 6b, $P>0.05$ ). Collectively, these data demonstrated that RhoA/MLC signaling was the

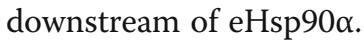

\section{Discussion}

In this study, we first propose a novel mechanism that eHsp90 $\alpha$ mediates HDM-induced human bronchial epithelial barrier dysfunction via activating RhoA/MLC signaling.

Epithelial hyperpermeability and disruption of AJ proteins are used for assessing the epithelial barrier dysfunction. Hyperpermeability of bronchial epithelium can result in greater penetration of inhaled allergens and particles into the subepithelial space, facilitating antigen sampling and innate and adaptive immune responses [46]. AJs are important for initiation and maintenance of cell-cell adhesion and are involved in numerous signal transduction cascades $[47,48]$. We previously identified that mice sensitized and challenged with $400 \mathrm{U} / \mathrm{ml}$ HDM could exhibit the typical features of atopic asthma: AHR, high serum IgE and eosinophilic airway inflammation [41]. In clinic, $\operatorname{HDM}(100-100,000 \mathrm{U} / \mathrm{ml}$, Alutard) is mainly used for immunotherapy [49]. In this study, the concentrations of HDM we used ranged from $200 \mathrm{U} / \mathrm{ml}$ to $1200 \mathrm{U} / \mathrm{ml}$, which also complied with the clinical application. Here we found that HDM increased epithelial permeability and disrupted the integration of $\mathrm{E}$ cadherin/ $\beta$-catenin complex in the membrane, but didn't affect their expression. The original TEER value in $\operatorname{HDM}(400 \mathrm{U} / \mathrm{ml})$ group $\left(15.87 \pm 1.7 \Omega . \mathrm{cm}^{2}\right)$ decreased compared to con group $\left(25.2 \pm 1.1 \Omega . \mathrm{cm}^{2}\right)$, and the original lower chamber fluorescence value of FITC-DX in $\operatorname{HDM}(400 \mathrm{U} / \mathrm{ml})$ group (425.50 \pm 13.92 a.u.) increased compared to con group $(358.67 \pm 12.01$ a.u.). These results were in agreement with the study that HDM did not affect expression of E-cadherin protein [50] but disagreement with another study that HDM induced the 

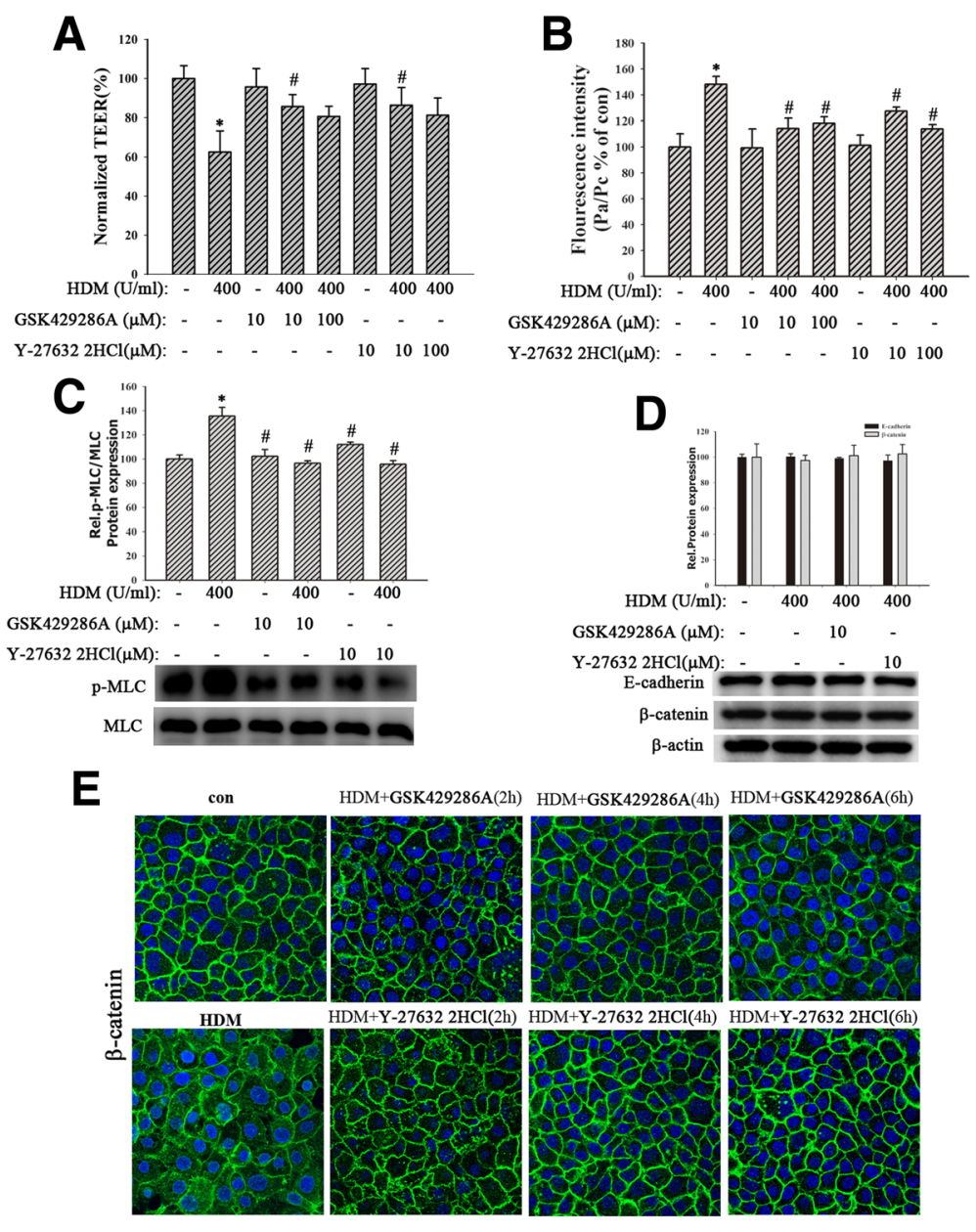

HDM+GSK429286A(2h) $\quad \mathrm{HDM}+\mathrm{GSK} 429286 \mathrm{~A}(4 \mathrm{~h}) \quad \mathrm{HDM}+\mathrm{GSK} 429286 \mathrm{~A}(6 \mathrm{~h})$

Control
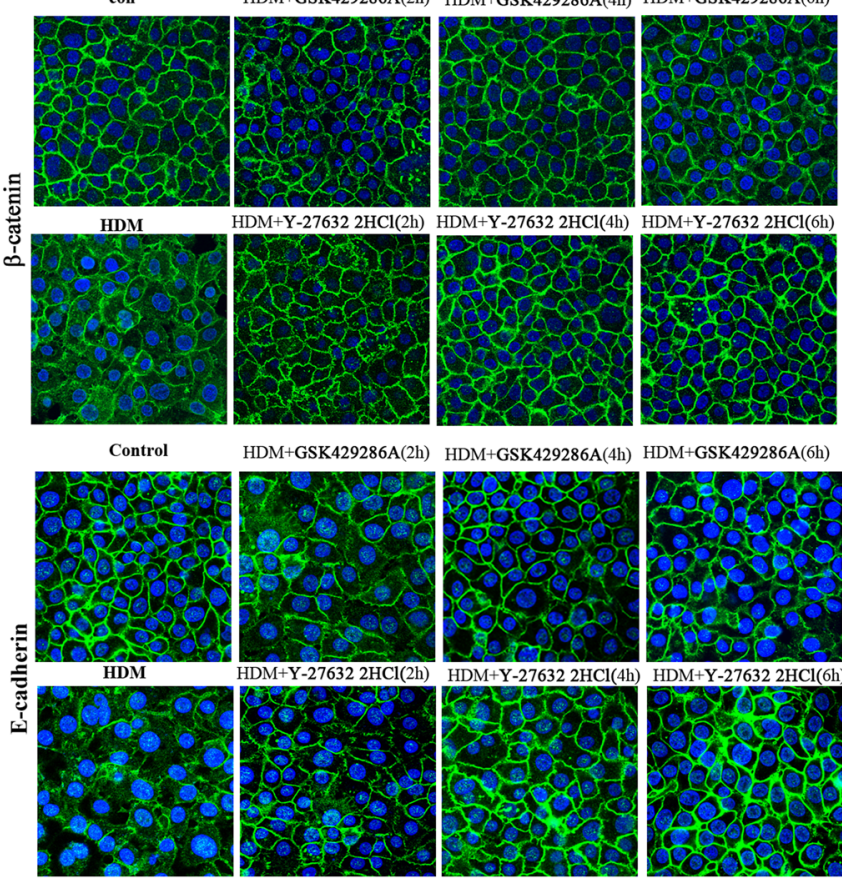

HDM+GSK429286A(4h) HDM+GSK429286A(6h)

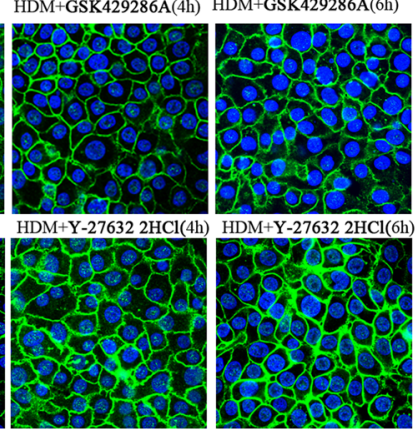

Fig. 4 Inhibition of RhoA/MLC signaling alleviated HDM-induced bronchial epithelial barrier dysfunction. a and b Cells pretreated for $6 \mathrm{~h}$ with inhibitors of RhoA/MLC signaling, Y-27632 2HCl (10, $100 \mu \mathrm{M})$ and GSK429286A (10, $100 \mu \mathrm{M})$, were exposed to HDM $(400 \mathrm{U} / \mathrm{ml})$ for $24 \mathrm{~h}$. TEER values and FITC-DX were measured immediately. c MLC and P-MLC were detected. $\mathbf{d}$ The expression of E-cadherin and $\beta$-catenin was detected. Data are mean \pm SD of three independent experiments. e The location of E-cadherin and $\beta$-catenin was detected by immunofluorescence staining. Data are mean \pm SD of four independent experiments. ${ }^{*} P<0.05$ versus con group; ${ }^{\#} P<0.05$ versus HDM group

downregulation of E-cadherin expression [40]. Consistently, we also identified that HDM promoted the distribution of E-cadherin and $\beta$-catenin. It indicated that the locations of E-cadherin and $\beta$-catenin were more essential to maintain cell-cell adhesion than the level of proteins expression. Collectively, our results revealed that HDM induced the delocalization of E-cadherin and $\beta$ - catenin, promoting the defect of bronchial epithelial barrier function.

For the exact mechanisms of bronchial epithelial barrier dysfunction induced by HDM are still largely unknown, we first demonstrated the involvement of eHsp90 $\alpha$ in this process. Hsp90 plays a critical role in many biological processes, such as inflammation and 

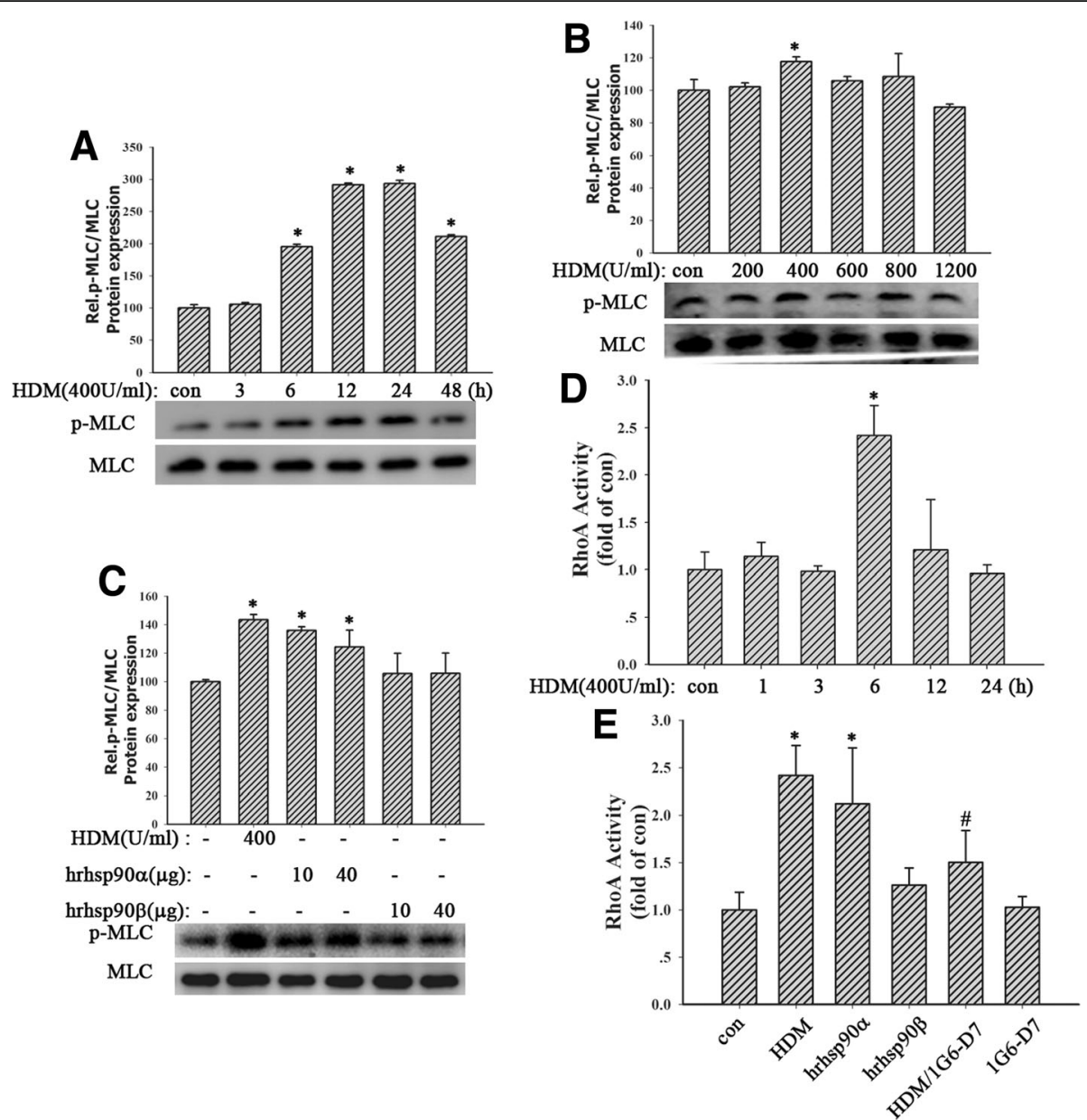

Fig. 5 HDM and hrHsp90a increased the levels of RhoA activity and MLC phosphorylation. a and b 16HBE cells were treated with HDM (200, 400, $600,800$, or $1200 \mathrm{U} / \mathrm{ml})$ for $24 \mathrm{~h}$ or stimulated with $\mathrm{HDM}(400 \mathrm{U} / \mathrm{ml})$ for 3, 6, 12, 24, or $48 \mathrm{~h}$. MLC and p-MLC were detected. c Cells were exposed to HDM $(400 \mathrm{U} / \mathrm{ml})$, hrHsp90a $(10,40 \mathrm{\mu g} / \mathrm{ml})$ or hrHsp90ß $(10,40 \mathrm{\mu g} / \mathrm{ml})$ for $24 \mathrm{~h}$. MLC and p-MLC were detected. d Cells exposed to HDM (400 $\mathrm{U} / \mathrm{ml}$ ) for $1,3,6,12,24 \mathrm{~h}$. Then RhoA activity was measured by Rho G-LISA RhoA activation assay kit ${ }^{\mathrm{TM}}$ biochem kit. e $16 \mathrm{HBE}$ cells pretreated with 1G6-D7 $(30 \mu \mathrm{g} / \mathrm{ml})$ for $2 \mathrm{~h}$ and then stimulated with HDM $(400 \mathrm{U} / \mathrm{ml})$, hrHsp90a $(10 \mu \mathrm{g} / \mathrm{ml})$ or hrHsp90ß $(10 \mu \mathrm{g} / \mathrm{ml})$ for $6 \mathrm{~h}$. RhoA activity was measured. Data are mean \pm SD of three independent experiments. ${ }^{*} P<0.05$ versus con group; ${ }^{\#} P<0.05$ versus HDM group

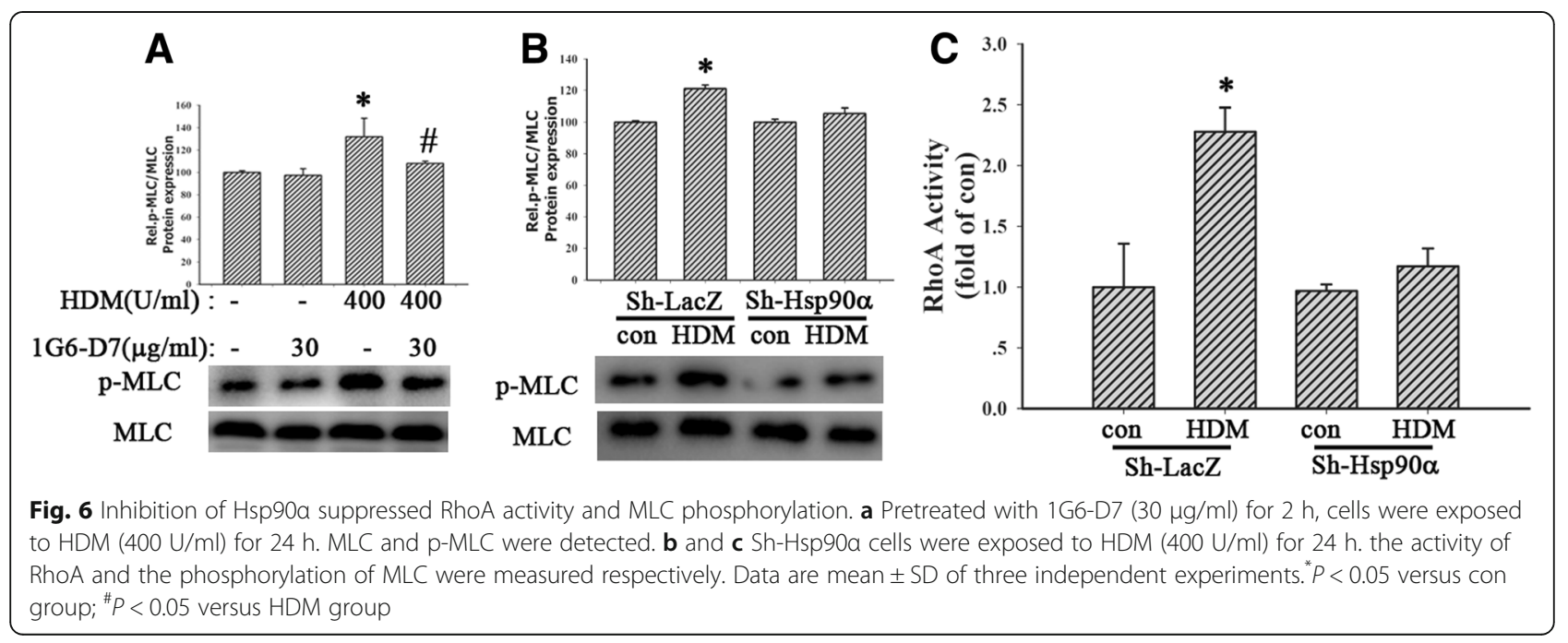


barrier function [14-16]. Early studies also indicated that Hsp90 mRNA and protein expression were increased in asthmatic patients $[13,14]$, suggesting the potential role of Hsp90 in asthma. In this study, we observed that HDM increased the secretion of Hsp90 $\alpha$ in $16 \mathrm{HBE}$ cells, coupled with the upregulation of Hsp90 $\alpha$ protein. Catravaset al demonstrated that Hsp90 mediated endothelial barrier dysfunction [11, 44]. Inhibition of Hsp90 improved the loss of microvascular endothelial and intestinal epithelial barrier integrity $[10,44]$, indicating the involvement of Hsp90 in barrier disruption. To our knowledge, Hsp90 $\beta$ mainly acts as a molecular chaperone protein and is essential for life $[17,18]$. While Hsp90 $\alpha$ secreted by cells exerts pro-mobility signal, which is involved in wound healing and tumor invasion [9]. Therefore, our study focused on the effect of Hsp90 $\alpha$ on bronchial barrier function. This study found that defects in barrier structure and function were observed in human bronchial epithelial monolayers stimulated with hrHsp90 $\alpha$ instead of hrHsp90ß, paralleled with the increasing expression and secretion of Hsp90 $\alpha$ in HDM-treated 16HBE cells. These results indicated that $\mathrm{Hsp} 90 \alpha$ was critical in HDM-induced bronchial barrier dysfunction. To further explore the exact role of Hsp90 $\alpha$ on airway barrier dysfunction induced by HDM, we successfully knocked down the protein expression of Hsp90 $\alpha$ in 16HBE cells by using lentivirus system technique. Expectedly, Hsp90 $\alpha$-silencing cells exhibited a remarkable improvement of epithelial hyperpermeability induced by HDM, suggesting that HDM caused barrier dysfunction partly in an Hsp90 $\alpha$-dependent manner. Besides, many studies have showed that eHsp90 participates in TGF- $\beta$ mediated collagen production in myocardial fibroblasts [23], wound healing in keratinocytes [9, 24] and contributes to tumor growth, invasion, and inflammatory storm [9, 25-29]. Taken together, these prompted us to infer that eHsp $90 \alpha$ may play a critical role on HDMinduced bronchial barrier defects. 1G6-D7, a specific anti-secreted Hsp90 $\alpha \mathrm{mAb}$, recognizes and neutralizes eHsp90 $\alpha$ function $[30,31]$. In this study, 1G6-D7 pretreatment restored the fall of TEER and the raise of FITC-DX and the delocalization of E-cadherin and $\beta$ catenin, suggesting that eHsp90 $\alpha$ mediated bronchial epithelial barrier dysfunction induced by HDM. However, intracellular Hsp90 $\alpha$ may also be involved in the dysfunction of bronchial epithelial barrier, which needs to be clarified by specifically blocking the intracellular Hsp90 $\alpha$ without affecting eHsp90 $\alpha$.

We have identified that eHsp90 $\alpha$ mediates HDMinduced barrier dysfunction. However, the mechanism that eHsp90 $\alpha$ induce the disruption of the epithelial barrier is not well defined. Catravas JD, et al. reported Hsp90 inhibitors prevented LPS-induced endothelial barrier dysfunction by disrupting RhoA signaling [11], indicating that the RhoA/Rho-kinase pathway activated by Hsp90 could result in the endothelial barrier disruption. RhoA signaling plays important roles in many cellular functions, including contraction, motility and proliferation and barrier dysfunction [32-34]. Inhibition of Rho kinase reduced MLC phosphorylation, a target of the Rho/ROCK pathway, thus producing airway relaxation [51]. Cigarette smoke caused AJC disruption and increased epithelial permeability via triggering the RhoA/ROCK signaling pathway in bronchial epithelial cells [39]. In agreement with these findings, our study also found both HDM increased RhoA activity at $6 \mathrm{~h}$ and promoted MLC phosphorylation beginning $6 \mathrm{~h}$, which remained elevated for many hours. Both Rho kinase inhibitors, Y-27632 $2 \mathrm{HCl}$ and GSK429286A, restored epithelial hyperpermeability and AJC disassembly induced by HDM and hrHsp90 $\alpha$. Consistently, hrHsp90 $\alpha$ instead of hrHsp90 $\beta$ increased RhoA activity and MLC phosphorylation. We further observed that inhibition of eHsp90 $\alpha$ by1G6-D7 or Hsp90 $\alpha$-silencing suppressed the activation of RhoA/MLC signaling induced by HDM, suggesting that eHsp90 $\alpha$ secreted by HDM-treated cells increased epithelial permeability and promoted AJC disruption through RhoA/MLC signaling activation, leading to a loss of epithelial cell-cell contact. Previous study reported that RhoA signaling promoted endothelial MLC phosphorylation, cytoskeletal reorganization and thereby increased endothelial stress fiber formation, gap formation, and protein permeability [36]. Thus it may affect the organization of cytoskeleton anchoring with the plasma membrane and AJCs, contributing to the barrier dysfunction.

Here, we found that HDM induced RhoA activity at $6 \mathrm{~h}$ and MLC phosphorylation on Ser19/Thr18 began at $6 \mathrm{~h}$ and persisted for at least $18 \mathrm{~h}$ in bronchial epithelial cells. These results disagreed with the results observed in endothelial cells exposed to thrombin [33, 34, 52] or LPS [11]. The thrombin-induced MLC phosphorylation was acute (began at 5-10 min) and transient (persisted for $1 \mathrm{~h}$ ), which was correlated with the transiently inactivated MLC phosphatase and a peak in $\mathrm{Ca}^{2+}$ mobilization to produce maximal MLC phosphorylation [52]. On the other hand, LPS-induced RhoA activity at $2 \mathrm{~h}$ and MLC phosphorylation began at $2 \mathrm{~h}$ and persisted for hours partially in a Hsp90-dependent manner [11]. However, the results showed HDM induced RhoA activation and MLC phosphorylation partly through eHsp90 $\alpha$ secretion. Yet other mechanisms involved should also be considered. The receptor LRP-1, connecting eHsp90 $\alpha$ signaling to serine 473 phosphorylation in Akt kinase [53], may contribute to the activation of RhoA/MLC signaling.

One phenomenon we have to explain is that HDM induced activation of RhoA/MLC signaling at $6 \mathrm{~h}$ while eHsp90 $\alpha$ was detected at $24 \mathrm{~h}$. On the one hand, the 
level of eHsp90 $\alpha$ at earlier time $(<24 \mathrm{~h})$ is too little to detected by the method of concentration and purification of condition media. Thus we can't compare the level of eHsp90 $\alpha$ between con and HDM groups. On the other hand, we detected that the Hsp90 $\alpha$ protein expression in HDM-treated cells remarkably increased at $6 \mathrm{~h}$. Most importantly, both blocking eHsp $90 \alpha$ by 1G6-D7 and knocking down Hsp90 $\alpha$ protein expression inhibited the activity of RhoA and the phosphorylation of MLC induced by HDM, indicating that eHsp90 $\alpha$ mediated the activation of RhoA/MLC signaling.

However, one limitation of this study is the use of $16 \mathrm{HBE}$ cells rather than primary bronchial epithelial cells from donors (health or asthma), which are also important for providing more evidences to validate our findings.

\section{Conclusion}

In summary, we first demonstrate that HDM increases the production of eHsp90 $\alpha$ and activates RhoA/MLC signaling in $16 \mathrm{HBE}$ cells. Neutralization of eHsp90 $\alpha$ by 1G6-D7inhibits the activation of RhoA/MLC and ameliorates bronchial epithelial barrier dysfunction induced by HDM. Moreover, inhibition of RhoA/MLC signaling prevents and restores epithelial hyperpermeability and AJC disruption induced by HDM or hrHsp90 $\alpha$, indicating the critical role of RhoA/MLC signaling in bronchial barrier dysfunction. Collectively, eHsp $90 \alpha$ mediates HDM-induced human bronchial epithelial barrier dysfunction partially by activating RhoA/MLC signaling. And the newly generated mAb, 1G6-D7, which selectively targets the dual lysine region in secreted $\mathrm{Hsp} 90 \alpha$, could be a novel agent for the treatment of asthma.

\begin{abstract}
Abbreviations
16HBE: Human bronchial epithelial cell line 16HBE140-; AJC: AJs complex; AJs: Adherens junctions; ANOVA: One-way analysis of variance; DAPI: 4',6diamidino-2-phenylindole dihydrochloride; EHsp: 90a extracellularhsp90a; FITC-DX: FITC-dextran flux; HDM: House dust mite; Hr: Human recombinant; HRP: Horseradish peroxidase; Hsp: Heat shock protein; MAb: Monoclonal antibody; MLC: Myosin light chain; p-MLC: Phospho-MLC; ROCK: Rho kinase; SD: Means \pm standard deviations; TEER: Transepithelial electrical resistance; TJs: Tight junctions
\end{abstract}

\section{Acknowledgements}

Not applicable.

\section{Funding}

The design and performance of this study were funded by the National Natural Science Foundation of China $(81670026,81500023,81470228$, $81270087,81270089)$. The data analysis of this study was funded by the Precision Medicine Research of The National Key Research and Development Plan of China (2016YFC0905800) and the National 973Program on Key Basic Research Project of China (973 Program, 2012CB518203). And the writing of this study was funded by the Natural Science Foundation of Guangdong Province (2014A030310325).

\section{Availability of data and materials}

The data set during and/or analyzed during the current study available from the corresponding author on reasonable request.

\section{Authors' contributions}

Shao-xi Cai, Hang-ming Dong and Yan-qing Le designed the experiment and wrote the manuscript. Hang-ming Dong, Yan-qing Le and Yan-hong Wang performed the experiments and analyzed the data. Hai-jinZhao helped with data analysis and revised the manuscript. Wei Li, Chao-wenHuang, Ya-hui Hu, Li-shan Luo, Xuan Wan, Yi-lan Wei and Zi-qiang Chu helped revise the manuscript. All authors reviewed the manuscript. All authors read and approved the final manuscript.

\section{Competing interests}

The authors declare that they have no competing interests.

\section{Consent for publication}

All the authors declare that they are consent for the publication.

\section{Ethics approval and consent to participate}

Not applicable.

\section{Publisher's Note}

Springer Nature remains neutral with regard to jurisdictional claims in published maps and institutional affiliations.

\section{Author details \\ ${ }^{1}$ Chronic Airways Diseases Laboratory, Department of Respiratory and Critical Care Medicine, NanFang Hospital, Southern Medical University, Guangzhou 510515, China. ${ }^{2}$ Department of Dermatology and the Norris Comprehensive Cancer Centre, University of Southern California Keck, Medical Centre, Los Angeles, CA 90033, USA.}

Received: 12 January 2017 Accepted: 19 May 2017

Published online: 30 May 2017

\section{References}

1. Nawijn MC, Hackett TL, Postma DS, van Oosterhout AJ, Heijink IH. Ecadherin: gatekeeper of airway mucosa and allergic sensitization. Trends Immunol. 2011;32:248-55.

2. Heijink IH, van Oosterhout A, Kapus A. Epidermal growth factor receptor signalling contributes to house dust mite-induced epithelial barrier dysfunction. Eur Respir J. 2010;36:1016-26.

3. Holgate ST. The airway epithelium is central to the pathogenesis of asthma. Allergol Int. 2008:57:1-10.

4. de Boer WI, Sharma HS, Baelemans SM, Hoogsteden HC, Lambrecht BN, Braunstahl GJ. Altered expression of epithelial junctional proteins in atopic asthma: possible role in inflammation. Can J Physiol Pharmacol. 2008;86: 105-12.

5. Trautmann A, Kruger K, Akdis M, Muller-Wening D, Akkaya A, Brocker EB, et al. Apoptosis and loss of adhesion of bronchial epithelial cells in asthma. Int Arch Allergy Immunol. 2005;138:142-50.

6. Tian X, Liu Z, Niu B, Zhang J, Tan TK, Lee SR, et al. E-cadherin/beta-catenin complex and the epithelial barrier. J Biomed Biotechnol. 2011;2011:567305.

7. Hackett TL, Warner SM, Stefanowicz D, Shaheen F, Pechkovsky DV, Murray $L A$, et al. Induction of epithelial-mesenchymal transition in primary airway epithelial cells from patients with asthma by transforming growth factorbeta1. Am J Respir Crit Care Med. 2009;180:122-33.

8. Mahalingam D, Swords R, Carew JS, Nawrocki ST, Bhalla K, Giles FJ. Targeting HSP90 for cancer therapy. Br J Cancer. 2009;100:1523-9.

9. Li W, Sahu D, Tsen F. Secreted heat shock protein-90 (Hsp90) in wound healing and cancer. Biochim Biophys Acta. 1823;2012:730-41.

10. Zhao Y, Huang ZJ, Rahman M, Luo Q, Thorlacius H. Radicicol, an Hsp90 inhibitor, inhibits intestinal inflammation and leakage in abdominal sepsis. J Surg Res. 2013;182:312-8.

11. Joshi AD, Dimitropoulou C, Thangjam G, Snead C, Feldman S, Barabutis N, et al. Heat shock protein 90 inhibitors prevent LPS-induced endothelial barrier dysfunction by disrupting RhoA signaling. Am J Respir Cell Mol Biol. 2014:50:170-9.

12. Chatterjee A, Dimitropoulou C, Drakopanayiotakis F, Antonova G, Snead C, Cannon J, et al. Heat shock protein 90 inhibitors prolong survival, attenuate inflammation, and reduce lung injury in murine sepsis. Am J Respir Crit Care Med. 2007;176:667-75. 
13. Tong W, Luo W. Heat shock proteins mRNA expressions by peripheral blood mononuclear cells in asthma and chronic bronchitis. Chin Med J (Engl). 2000;113:175-7

14. Perisic T, Sreckovic M, Matic G. An imbalance in antioxidant enzymes and stress proteins in childhood asthma. Clin Biochem. 2007;40:1168-71.

15. Lee MY, Sun $\mathrm{KH}$, Chiang $C P$, Huang $C F$, Sun GH, Tsou YC, et al. Nitric oxide suppresses LPS-induced inflammation in a mouse asthma model by attenuating the interaction of IKK and Hsp90. Exp Biol Med (Maywood). 2015;240:498-507

16. Intapad S, Dimitropoulou C, Snead C, Piyachaturawat P, Catravas JD. Regulation of asthmatic airway relaxation by estrogen and heat shock protein 90. J Cell Physiol. 2012;227:3036-43.

17. Jayaprakash P, Dong H, Zou M, Bhatia A, O'Brien K, Chen M, et al. Hsp90alpha and Hsp90beta together operate a hypoxia and nutrient paucity stress-response mechanism during wound healing. J Cell Sci. 2015; 128:1475-80.

18. Voss AK, Thomas T, Gruss P. Mice lacking HSP90beta fail to develop a placental labyrinth. Development. 2000;127:1-11.

19. Hightower LE, Guidon Jr PT. Selective release from cultured mammalian cells of heat-shock (stress) proteins that resemble glia-axon transfer proteins. J Cell Physiol. 1989;138:257-66.

20. Li W, Li Y, Guan S, Fan J, Cheng CF, Bright AM, et al. Extracellular heat shock protein-90alpha: linking hypoxia to skin cell motility and wound healing Embo J. 2007;26:1221-33.

21. Yu X, Harris SL, Levine AJ. The regulation of exosome secretion: a novel function of the p53 protein. Cancer Res. 2006;66:4795-801.

22. Cheng CF, Fan J, Fedesco M, Guan S, Li Y, Bandyopadhyay B, et al. Transforming growth factor alpha (TGFalpha)-stimulated secretion of HSP90alpha: using the receptor LRP-1/CD91 to promote human skin cell migration against a TGFbeta-rich environment during wound healing. $\mathrm{Mol}$ Cell Biol. 2008;28:3344-58.

23. Garcia R, Merino D, Gomez JM, Nistal JF, Hurle MA, Cortajarena AL, et al. Extracellular heat shock protein 90 binding to TGFbeta receptor I participates in TGFbeta-mediated collagen production in myocardial fibroblasts. Cell Signal. 2016;28:1563-79.

24. Bhatia A, O'Brien K, Chen M, Woodley DT, Li W. Keratinocyte-secreted heat shock protein-90alpha: leading wound reepithelialization and closure. Adv Wound Care (New Rochelle). 2016:5:176-84.

25. Nolan KD, Franco OE, Hance MW, Hayward SW, Isaacs JS. Tumor-secreted Hsp90 subverts polycomb function to drive prostate tumor growth and invasion. J Biol Chem. 2015;290:8271-82.

26. Bohonowych JE, Hance MW, Nolan KD, Defee M, Parsons CH, Isaacs JS. Extracellular Hsp90 mediates an NF-kappaB dependent inflammatory stromal program: implications for the prostate tumor microenvironment. Prostate. 2014;74:395-407.

27. Sahu D, Zhao Z, Tsen F, Cheng CF, Park R, Situ AJ, et al. A potentially common peptide target in secreted heat shock protein-90alpha for hypoxia-inducible factor-1alpha-positive tumors. Mol Biol Cell. 2012;23:602-13.

28. Chen WS, Chen CC, Chen LL, Lee CC, Huang TS. Secreted heat shock protein 90alpha (HSP90alpha) induces nuclear factor-kappaB-mediated TCF12 protein expression to down-regulate E-cadherin and to enhance colorectal cancer cell migration and invasion. J Biol Chem. 2013;288:9001-10.

29. Stellas D, El Hamidieh A, Patsavoudi E. Monoclonal antibody 4C5 prevents activation of MMP2 and MMP9 by disrupting their interaction with extracellular HSP90 and inhibits formation of metastatic breast cancer cell deposits. BMC Cell Biol. 2010;11:51.

30. Zou M, Bhatia A, Dong H, Jayaprakash P, Guo J, Sahu D, et al. Evolutionarily conserved dual lysine motif determines the non-chaperone function of secreted Hsp90alpha in tumour progression. Oncogene. 2017;36(15):2160-71.

31. Dong H, Zou M, Bhatia A, Jayaprakash P, Hofman F, Ying Q, et al. Breast cancer MDA-MB-231 cells use secreted heat shock protein-90alpha (Hsp90alpha) to survive a hostile hypoxic environment. Sci Rep. 2016:6:20605.

32. Shimokawa H, Sunamura S, Satoh K. RhoA/Rho-kinase in the cardiovascular system. Circ Res. 2016;118:352-66.

33. van Nieuw Amerongen GP, Vermeer MA, van Hinsbergh WW. Role of RhoA and Rho kinase in lysophosphatidic acid-induced endothelial barrier dysfunction. Arterioscler Thromb Vasc Biol. 2000;20:E127-33.

34. van Nieuw Amerongen GP, van Delft S, Vermeer MA, Collard JG, van Hinsbergh W. Activation of RhoA by thrombin in endothelial hyperpermeability: role of Rho kinase and protein tyrosine kinases. Circ Res. 2000;87:335-40
35. Fukata Y, Amano M, Kaibuchi K. Rho-Rho-kinase pathway in smooth muscle contraction and cytoskeletal reorganization of non-muscle cells. Trends Pharmacol Sci. 2001;22:32-9.

36. Clements RT, Minnear FL, Singer HA, Keller RS, Vincent PA. RhoA and Rhokinase dependent and independent signals mediate TGF-beta-induced pulmonary endothelial cytoskeletal reorganization and permeability. Am J Physiol Lung Cell Mol Physiol. 2005;288:L294-306.

37. Tong J, Wang Y, Chang B, Zhang D, Wang B. Evidence for the involvement of RhoA signaling in the ethanol-induced increase in intestinal epithelial barrier permeability. Int J Mol Sci. 2013;14:3946-60.

38. Edlund $\mathrm{S}$, Landstrom $\mathrm{M}$, Heldin $\mathrm{CH}$, Aspenstrom $\mathrm{P}$. Transforming growth factor-beta-induced mobilization of actin cytoskeleton requires signaling by small GTPases Cdc42 and RhoA. Mol Biol Cell. 2002;13:902-14.

39. Forteza RM, Casalino-Matsuda SM, Falcon NS, Valencia Gattas M, Monzon ME. Hyaluronan and layilin mediate loss of airway epithelial barrier function induced by cigarette smoke by decreasing E-cadherin. J Biol Chem. 2012; 287:42288-98.

40. Zhang R, Dong H, Zhao H, Zhou L, Zou F, Cai S. 1,25-Dihydroxyvitamin D3 targeting VEGF pathway alleviates house dust mite (HDM)-induced airway epithelial barrier dysfunction. Cell Immunol. 2017;312:15-24.

41. Huang C, Dong H, Zou M, Luo L, Hu Y, Xie Z, et al. Bevacizumab reduced auto-phosphorylation of VEGFR2 to protect HDM-induced asthma mice. Biochem Biophys Res Commun. 2016;478:181-6.

42. Huang $W$, Zhao H, Dong H, Wu Y, Yao L, Zou F, et al. High-mobility group box 1 impairs airway epithelial barrier function through the activation of the RAGE/ERK pathway. Int J Mol Med. 2016;37:1189-98.

43. Steelant B, Farre R, Wawrzyniak P, Belmans J, Dekimpe E, Vanheel H, et al. Impaired barrier function in patients with house dust mite-induced allergic rhinitis is accompanied by decreased occludin and zonula occludens-1 expression. J Allergy Clin Immunol. 2016;137:1043-53. e1041-1045.

44. Antonov A, Snead C, Gorshkov B, Antonova GN, Verin AD, Catravas JD. Heat shock protein 90 inhibitors protect and restore pulmonary endothelial barrier function. Am J Respir Cell Mol Biol. 2008:39:551-9.

45. Wang Z, Ginnan R, Abdullaev IF, Trebak M, Vincent PA, Singer HA. Calcium/ Calmodulin-dependent protein kinase II delta 6 (CaMKIldelta6) and RhoA involvement in thrombin-induced endothelial barrier dysfunction. J Biol Chem. 2010:285:21303-12

46. Georas SN, Rezaee F. Epithelial barrier function: at the front line of asthma immunology and allergic airway inflammation. J Allergy Clin Immunol. 2014; 134:509-20.

47. Niessen CM. Tight junctions/adherens junctions: basic structure and function. J Invest Dermatol. 2007:127:2525-32

48. Matter K, Balda MS. Signalling to and from tight junctions. Nat Rev Mol Cell Biol. 2003:4:225-36.

49. Dong $X$, Huang N, Li W, Hu L, Wang $X$, Wang $Y$, et al. Systemic reactions to dust mite subcutaneous immunotherapy: a 3-year follow-up study. Allergy, Asthma Immunol Res. 2016;8:421-7

50. Heijink IH, Postma DS, Noordhoek JA, Broekema M, Kapus A. House dust mite-promoted epithelial-to-mesenchymal transition in human bronchial epithelium. Am J Respir Cell Mol Biol. 2010;42:69-79.

51. Gerthoffer WT, Solway J, Camoretti-Mercado B. Emerging targets for novel therapy of asthma. Curr Opin Pharmacol. 2013;13:324-30.

52. Essler M, Amano M, Kruse HJ, Kaibuchi K, Weber PC, Aepfelbacher M. Thrombin inactivates myosin light chain phosphatase via Rho and its target Rho kinase in human endothelial cells. J Biol Chem. 1998;273:21867-74.

53. Tsen F, Bhatia A, O'Brien K, Cheng CF, Chen M, Hay N, et al. Extracellular heat shock protein 90 signals through subdomain II and the NPVY motif of LRP-1 receptor to Akt1 and Akt2: a circuit essential for promoting skin cell migration in vitro and wound healing in vivo. Mol Cell Biol. 2013:33:4947-59. 